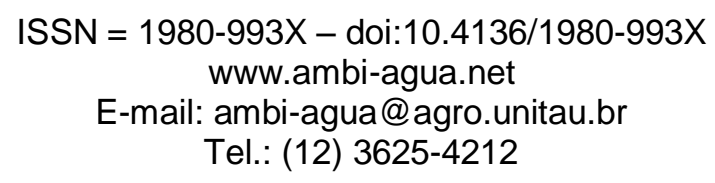

\title{
Vazão ecológica e disponibilidade hídrica na bacia das Pedras, Guarapuava-PR
}

\author{
(http://dx.doi.org/10.4136/ambi-agua.840)
}

\section{Leandro Redin Vestena ${ }^{1}$; Éderson Dias de Oliveira ${ }^{1}$; Márcia Cristina da Cunha ${ }^{1}$; Edivaldo Lopes Thomaz}

\author{
Programa de Pós-Graduação em Geografia, Universidade Estadual do Centro-Oeste \\ Unicentro, Guarapuava, Paraná, Brasil, \\ e-mails: vestena@unicentro.br, edersonjandaia@hotmail.com, \\ marcia1cunha@yahoo.com.br, thomaz@unicentro.br
}

\section{RESUMO}

O conhecimento da vazão ecológica é de suma importância para se determinar a disponibilidade hídrica, visando ao gerenciamento dos recursos hídricos. O presente estudo estimou a vazão ecológica e avaliou a disponibilidade hídrica em um trecho do rio das Pedras, manancial da cidade de Guarapuava, região Centro-Sul do Estado do Paraná. Para tal, aplicaram-se diferentes métodos empregados no Brasil para obtenção da vazão ecológica, uma vazão de referência à concessão de outorgas, e avaliou-se o regime fluvial. Os métodos utilizados foram média mínima de sete dias com período de retorno de dez anos, vazões associadas às permanências de $95 \%$ e $90 \%$, vazões mínimas anuais de sete dias e vazão aquática de base. Os dados de vazão utilizados foram da estação fluviométrica localizada na ETA (Estação de Captação de Água de Guarapuava). Conclui-se que o débito fluvial anual, entre os anos de 1985 e 2009, apresentou uma média diária de $9,12 \mathrm{~m}^{3} \mathrm{~s}^{-1}$ e uma mediana de $9,16 \mathrm{~m}^{3} \mathrm{~s}^{-1}$. A vazão ecológica estimada pelos métodos utilizados para o trecho do rio das Pedras variou de 1,72 a $2,74 \mathrm{~m}^{3} \mathrm{~s}^{-1}$, com uma média de $2,20 \mathrm{~m}^{3} \mathrm{~s}^{-1}$, e coeficiente de variação de $19,5 \%$. A vazão ecológica estimada para o trecho foi de $0,91 \mathrm{~m}^{3} \mathrm{~s}^{-1}$, conforme os critérios adotados no Estado do Paraná. No trecho avaliado, a relação entre a vazão diária e o volume outorgado indica a ineficiência dos métodos avaliados na determinação da vazão ecológica, ou seja, eles não garantiram o volume de água mínimo necessário à conservação do ecossistema fluvial.

Palavras-chave: vazão ambiental, regime fluvial, bacia hidrográfica, ecossistema fluvial.

\section{Instream flow and water availability in the Rio das Pedras basin, Guarapuava-PR, Brazil}

\begin{abstract}
Knowledge of instream flow is of paramount importance to determine water availability for water resources management. This study estimated instream flow and evaluated water availability in the stretch of the Rio das Pedras, which supplies water to Guarapuava, a town in the mid-southern region of the state of Paraná, Brazil. Several different methods were employed to obtain instream flow, a reference discharge for water consumption permit, and the river regime. Methods comprised 7-day mean minimum with a 10-year return period, discharges associated to $95 \%$ and $90 \%$ permanence, yearly 7 -day mean minimum discharge and basic water discharge. Discharge data were obtained from the meteorological station at
\end{abstract}


VESTENA, L. R.; OLIVEIRA, E. D.; CUNHA, M. C.; THOMAZ, E. L. Vazão ecológica e disponibilidade hídrica na bacia das Pedras, Guarapuava-PR. Ambi-Agua, Taubaté, v. 7, n. 3, p. 212-227, 2012. (http://dx.doi.org/10.4136/ambi-agua.840)

the Water Station of Guarapuava (ETA). Results show that yearly river debit between 1985 and 2009 had a daily mean of $9.12 \mathrm{~m}^{3} \mathrm{~s}^{-1}$ and a median discharge of $9.16 \mathrm{~m}^{3} \mathrm{~s}^{-1}$. Estimated instream flow, measured by methods used for the Rio das Pedras stretch, ranged from 1.72 to $2.74 \mathrm{~m}^{3} \mathrm{~s}^{-1}$, with an average of $2.20 \mathrm{~m}^{3} \mathrm{~s}^{-1}$ and a coefficient of variation of $19.5 \%$. Discharge for the stretch was estimated as $0.91 \mathrm{~m}^{3} \mathrm{~s}^{-1}$, following criteria used in the state of Paraná. The relationship of the evaluated stretch between daily flow and the intake volume granted by the government revealed the inefficiency of the applied methods for instream flow assessment. In fact, they failed to warrant a minimum water volume required for the conservation of the river ecosystem.

Keywords: instream flow, river regime, hydrographic basin, river ecosystem.

\section{INTRODUÇÃO}

Os aspectos qualitativos e quantitativos dos recursos hídricos são essenciais à manutenção do equilíbrio ambiental de qualquer sistema fluvial. A variabilidade temporal e espacial da água, a demanda mundial crescente e o avanço da poluição hídrica vêm agravando as condições dos mananciais hídricos. Nos ambientes urbanos e rurais, essa relação é ainda mais dependente, sendo que a demanda por água só tem aumentado nas últimas décadas.

Mesmo com a captação de água se deve garantir nos corpos hídricos uma quantidade mínima de água, vital para a manutenção dos ecossistemas fluviais. Esta quantidade mínima é denominada de vazão ecológica ou ambiental, como também de águas residuais, águas remanescentes, vazão reduzida, dentre outras denominações. A vazão ecológica é a quantidade de água que deve permanecer no leito dos rios para atendimento das demandas do ecossistema aquático, para preservação da flora e da fauna relacionada ao corpo hídrico (Cruz, 2005; Medeiros et al., 2011).

Os métodos para determinação da vazão ecológica são vários. Eles são classificados de modo geral em função dos procedimentos metodológicos adotados para determinação da vazão ecológica, em hidrológicos (histórico do fluxo), hidráulicos (geometria hidráulica), hábitats e holísticos (Jowett, 1997, Sarmento, 2007).

$\mathrm{O}$ volume total de água utilizado de um curso fluvial para atender usos externos como abastecimento público, industrial, dessedentação animal, irrigação, energia elétrica etc. não devem afetar a vazão ecológica (Benetti et. al., 2003). No Brasil, as autorizações de uso de recursos hídricos são concedidas utilizando-se de um valor único de vazão ecológica, obtido geralmente por métodos hidrológicos que não consideram as limitações hídricas nos regimes naturais de vazões (a escala espaço-temporal e a variabilidade hidrológica) e os padrões dos hábitat (aspectos dos micro-hábitats ao longo do curso d'água com as mudanças de vazões) (Medeiros et al., 2011). Apesar das limitações destes métodos tradicionais, já apontadas por Collischon et al. (2005), Moliere et al. (2009) e Medeiros et al. (2011), no presente trabalho, eles serão utilizados para definição da vazão ecológica, por serem os métodos atualmente usados e definidos em legislação para a cessão de outorga no Brasil.

Diante disso, o planejamento e o gerenciamento de recursos hídricos são fundamentais para prevenir e minimizar problemas ambientais, à medida que garante uma quantidade mínima de vazão ecológica, fundamental à conservação do ecossistema fluvial. A vazão ecológica também possibilita identificar a disponibilidade de água real nos mananciais de uma determinada região, com potencialidade de serem captados e aproveitados.

No Brasil, para o aproveitamento dos recursos hídricos, são estabelecidos os valores máximos de retirada de volumes de água de um corpo hídrico, outorgados a usuários, a partir da disponibilidade hídrica real. "A Outorga é o ato administrativo que expressa os termos e as 
VESTENA, L. R.; OLIVEIRA, E. D.; CUNHA, M. C.; THOMAZ, E. L. Vazão ecológica e disponibilidade hídrica na bacia das Pedras, Guarapuava-PR. Ambi-Agua, Taubaté, v. 7, n. 3, p. 212-227, 2012. (http://dx.doi.org/10.4136/ambi-agua.840)

condições mediante as quais o Poder Público permite, por prazo determinado, o uso de recursos hídricos", visa assegurar o controle quantitativo e qualitativo dos usos da água e disciplinar o exercício dos direitos de acesso à água (Paraná, 2002; Instituto das Águas do Paraná, 2012).

A Outorga é dada a usuários após definir-se a vazão ecológica. Contudo, cada Estado da federação brasileira estabelece critérios de outorga e direito de uso da água, ou seja, possui um método, um critério para a definição da vazão ecológica. No Brasil, os critérios para definição da vazão ecológica basicamente são fundamentados em dados de séries históricas de vazão. No Quadro 1 é apresentado um resumo destes critérios.

Quadro 1. Critérios de outorga de direito de uso da água em alguns Estados brasileiros.

\begin{tabular}{|c|c|c|c|}
\hline Estado & $\begin{array}{c}\text { Vazão } \\
\text { referencial }\end{array}$ & Critério de Outorga (1) & $\begin{array}{l}\text { Vazão ecológica } \\
\text { indiretamente } \\
\text { estabelecida }\end{array}$ \\
\hline PR & $\mathrm{Q}_{7.10}$ & $50 \%$ da vazão referencial. & $50 \%$ da $Q_{7.10}$ \\
\hline \multirow{2}{*}{ MG } & \multirow{2}{*}{$\mathrm{Q}_{7.10}$} & $\begin{array}{l}30 \% \text { da vazão referencial em cursos d'água usuais. } \\
\text { Quando o interessado promover a regularização, o } \\
\text { limite poderá ser superior desde que seja mantida } \\
\text { uma vazão residual de } 70 \% \text { da vazão referencial. }\end{array}$ & $\mathrm{Q}_{7.10}$ \\
\hline & & $\begin{array}{l}\text { Poderão ser adotadas vazões residuais inferiores a } \\
70 \% \text { da vazão de referência, quando for de interesse } \\
\text { público e não causar prejuízos a terceiros. }\end{array}$ & $\begin{array}{l}\text { Exceção à regra } \\
\text { quando for de } \\
\text { interesse público }\end{array}$ \\
\hline \multirow[t]{2}{*}{$\mathrm{PE}$} & \multirow{2}{*}{$\mathrm{Q}_{90}$ diário } & $\begin{array}{l}80 \% \text { da vazão referencial quando não houver } \\
\text { barramento, ou quando houver barramento em cursos } \\
\text { d'água perenes. }\end{array}$ & $20 \%$ da $Q_{90}$ \\
\hline & & $\begin{array}{l}\text { 95\% da vazão referencial quando houver barramento } \\
\text { em curso d'água intermitente. }\end{array}$ & $5 \%$ da $\mathrm{Q}_{90}$ \\
\hline \multirow{3}{*}{ BA } & \multirow{3}{*}{ Q 90 diário } & $\begin{array}{l}80 \% \text { da vazão referencial quando não houver } \\
\text { barramento, ou quando houver barramento em cursos } \\
\text { d'água perenes. }\end{array}$ & $20 \%$ da $Q_{90}$ \\
\hline & & $\begin{array}{l}\text { 95\% da vazão referencial quando houver barramento } \\
\text { em curso d'água intermitente. } \\
\text { Quando o suprimento for para abastecimento } \\
\text { humano, o percentual pode atingir } 95 \% \text { da vazão } \\
\text { referencial. }\end{array}$ & $5 \%$ da $Q_{90}$ \\
\hline & & $\begin{array}{l}\text { No caso de vazões regularizadas por reservatórios, a } \\
\text { vazão residual de } 20 \% \text { da vazão referencial deve } \\
\text { escoar a jusante por descargas de fundo ou por } \\
\text { qualquer outro dispositivo que não inclua bombas de } \\
\text { recalques. Nenhum usuário individualmente receberá } \\
\text { outorga superior a } 210 \% \text { da vazão referencial em um } \\
\text { dado manancial. }\end{array}$ & $20 \%$ da $Q_{90}$ \\
\hline $\mathrm{PB}$ & \multirow{3}{*}{$\begin{array}{l}\text { Vazão } \\
\text { regularizada } \\
\text { com } 90 \% \text { de } \\
\text { garantia }\end{array}$} & $90 \%$ da vazão referencial & $10 \%$ da $Q_{90}$ \\
\hline $\mathrm{RN}$ & & $90 \%$ da vazão referencial & $10 \%$ da $Q_{90}$ \\
\hline $\mathrm{CE}$ & & $\begin{array}{l}90 \% \text { da vazão referencial em cursos d'água com } \\
\text { barramento; em lagos ou lagoas, } 33 \% \text { da vazão } \\
\text { referencial. }\end{array}$ & $\begin{array}{c}10 \% \text { ou } 67 \% \text { da } Q \\
90\end{array}$ \\
\hline
\end{tabular}

(1) Limite de autorização de retirada de água acumulada até a seção fluvial.

Fonte: Benetti et al. (2003). 
VESTENA, L. R.; OLIVEIRA, E. D.; CUNHA, M. C.; THOMAZ, E. L. Vazão ecológica e disponibilidade hídrica na bacia das Pedras, Guarapuava-PR. Ambi-Agua, Taubaté, v. 7, n. 3, p. 212-227, 2012. (http://dx.doi.org/10.4136/ambi-agua.840)

No caso do Estado do Paraná, a vazão ecológica é o volume de $50 \%$ da vazão de referência obtido da média mínima de sete dias com período de retorno de dez anos $\left.{ }_{7} \mathrm{Q}_{10}\right)$ (Paraná, 1999; Suderhsa, 2006). Entretanto, para a definição da vazão ecológica existem diversos procedimentos técnicos. De modo geral, os procedimentos fundamentam-se em dados de séries históricas de vazão, nas relações entre parâmetros hidráulicos e a vazão e nas relações entre o hábitat e a vazão.

A unidade territorial básica para o planejamento e o gerenciamento dos recursos hídricos é a bacia hidrográfica (Brasil, 1997). Ela é uma área da superfície terrestre delimitada topograficamente, cuja configuração resulta de uma série de elementos (geomorfológicos, pedológicos, hidrológicos, climáticos, fauna, flora e ocupação antrópica) que se sobrepõem no espaço, constituindo uma dinâmica própria, um sistema natural.

A quantificação da disponibilidade hídrica na bacia hidrográfica do rio das Pedras (BHRP) é de extrema importância por ser área de manancial da cidade de Guarapuava, principalmente no trecho do rio das Pedras onde é realizada a captação de água pela Companhia de Saneamento do Paraná (Sanepar). Portanto, o planejamento de uso e ocupação do solo é fundamental para o equilíbrio qualitativo e quantitativo dos recursos hídricos na BHRP.

O objetivo do presente estudo foi determinar a vazão ecológica e avaliar preliminarmente a disponibilidade hídrica na BHRP, manancial da cidade de Guarapuava, região Centro-Sul do Estado do Paraná, utilizando-se de diferentes métodos e critérios de referência para a vazão ecológica: a média mínima de sete dias com período de retorno de dez anos, a curva de permanência de vazões $\left(\mathrm{Q}_{90}\right.$ e $\left.\mathrm{Q}_{95}\right)$, a vazão aquática de base e as vazões mínimas anuais de sete dias.

Desse modo, a determinação da vazão ecológica por mais de um método e critério fornecerá informações com mais credibilidade como parâmetro orientador de outorga de uso de água, pois o conhecimento da quantidade mínima de água necessária à conservação do ecossistema fluvial possibilita o uso mais correto e racional dos recursos hídricos.

\section{MATERIAIS E MÉTODO}

\section{1. Área de estudo}

A bacia hidrográfica do rio das Pedras (BHRP) com área estimada em $332 \mathrm{~km}^{2}$ localizase no município de Guarapuava, região Centro-Sul do Estado do Paraná, entre as coordenadas UTM 22, 7.210.725 m e 7.186.234 $\mathrm{m} \mathrm{N}$ de latitude e $477.895 \mathrm{~m}$ e $451.960 \mathrm{~m}$ E de longitude, no meridiano central $51^{\circ}$ WGr (Figura 1).

Guarapuava está sob o domínio da zona extratropical, o que resulta em temperaturas com caráter mesotérmico, com médias anuais entre $16^{\circ}$ e $20^{\circ} \mathrm{C}$, inverno frio e verão amenizado pelas altitudes (Thomaz e Vestena, 2003). O clima do município de Guarapuava, segundo Köppen, classifica-se como $\mathrm{Cfb}$, o que significa que o clima é pluvial, sempre úmido, com verões chuvosos e frescos (Maack, 1981).

O rio das Pedras é um dos principais formadores do rio Jordão, que por sua vez é um dos maiores afluentes da margem direita do rio Iguaçu. As principais nascentes que formam o rio das Pedras encontram-se na Área de Proteção Ambiental (APA) da serra da Esperança. O seu sistema de drenagem, de acordo com a hierarquia de Strahler (1957), apresenta ramificação de $5^{\mathrm{a}}$ ordem.

A bacia se desenvolve no reverso da escarpa basáltica, localmente denominada serra da Esperança, sendo que, para Oeste, limita-se com o perímetro urbano de Guarapuava, com altitude que varia de $1.280 \mathrm{~m}$ na serra da Esperança até $950 \mathrm{~m}$ na desembocadura (Santos e Kobiyama, 2003). 
VESTENA, L. R.; OLIVEIRA, E. D.; CUNHA, M. C.; THOMAZ, E. L. Vazão ecológica e disponibilidade hídrica na bacia das Pedras, Guarapuava-PR. Ambi-Agua, Taubaté, v. 7, n. 3, p. 212-227, 2012. (http://dx.doi.org/10.4136/ambi-agua.840)

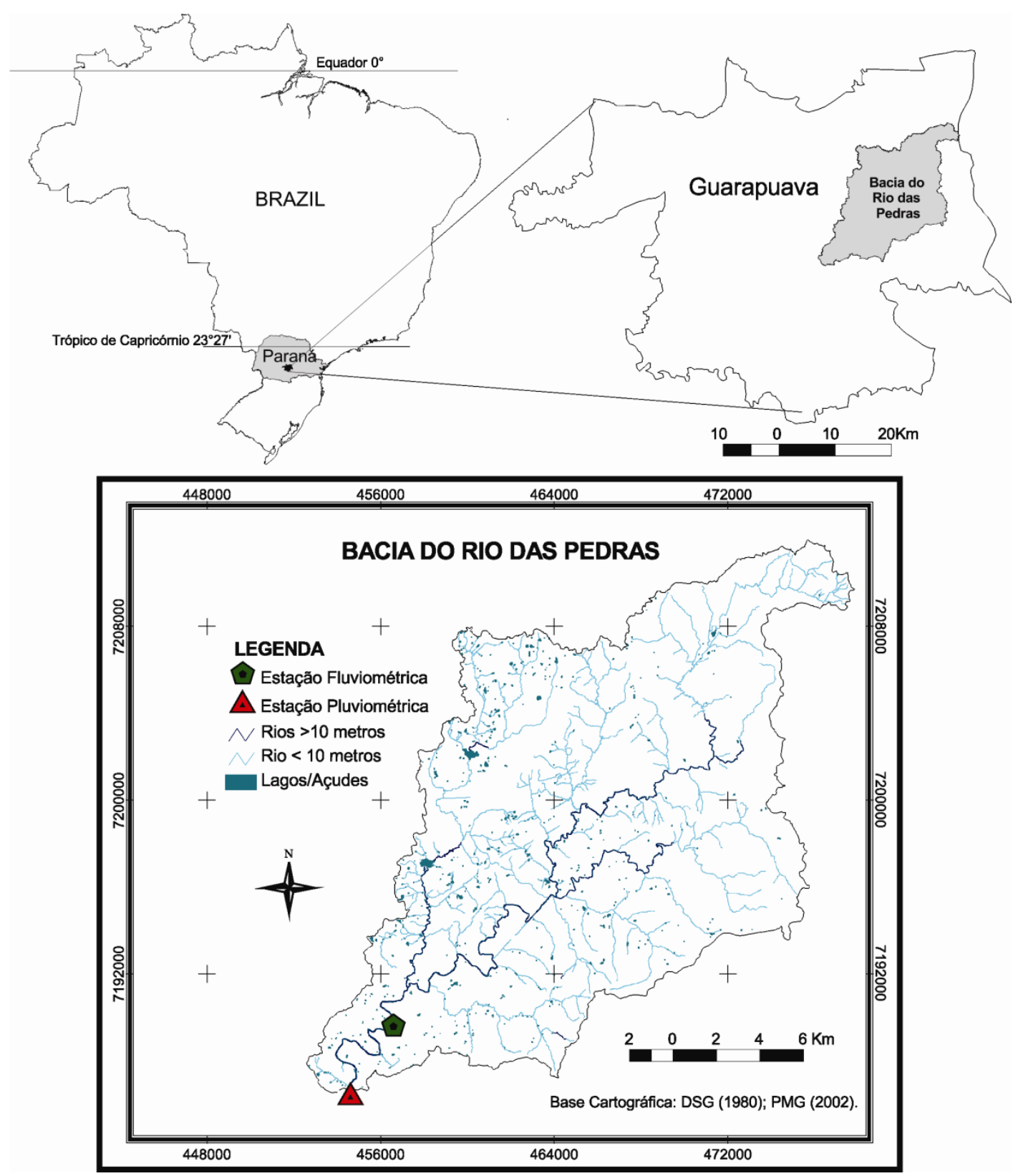

Figura 1. Localização da bacia hidrográfica do rio das Pedras e da estação fluviométrica (local de captação de água pela Sanepar) e pluviométrica utilizada.

O relevo da BHRP varia de plano a montanhoso, onde predominam os tipos suave ondulados e ondulados (declividades de até $12^{\circ}$ ) em $77 \%$ da área. Destaca-se ainda que mais de $20 \%$ da bacia apresenta relevos de forte ondulado a montanhoso (declividades maiores que $12^{\circ}$ ), que potencializa significativas energias aos fluxos superficiais.

Os principais tipos de solos que prevalecem na bacia são: Latossolo, Cambissolo, Neossolo (litólico) e Gleissolo (hidromórfico). Em algumas unidades, ocorrem inclusões de afloramento de rocha, pedregosidade e rochosidade em grau variado (Vestena e Thomaz, 2006).

A vegetação dominante da bacia é constituída de arbustos, florestas secundárias, que aparecem geralmente depois da terra ter sido cultivada, floresta subtropical perenifólia, reflorestamentos, vegetação campestre, campos alagados e pastagens (Santos e Kobiyama, 2003). 
VESTENA, L. R.; OLIVEIRA, E. D.; CUNHA, M. C.; THOMAZ, E. L. Vazão ecológica e disponibilidade hídrica na bacia das Pedras, Guarapuava-PR. Ambi-Agua, Taubaté, v. 7, n. 3, p. 212-227, 2012. (http://dx.doi.org/10.4136/ambi-agua.840)

O uso da terra é bastante diversificado, com atividades relacionadas à agricultura, mata, campo, pecuária, indústria entre outros. Porém, o uso da terra que mais se destaca é a associação de mata e campo que recobrem mais de $65 \%$ da área.

A cidade de Guarapuava passou por uma expansão física territorial urbana expressiva desde a década de 1970, quando surge grande número de loteamentos. A população cresceu significativamente, enquanto que a população rural manteve sua tendência de queda, que se acelerou após os anos de 1980. O município conta com uma população de 166.195 habitantes, dos quais 153.098 residem na área urbana, segundo dados obtidos pelo último censo (Brasil, 2010). Esse desenvolvimento urbano significativo se deve às várias mudanças na forma de apropriação da natureza, como a introdução de novas técnicas na agricultura, via de transporte, relações sociais e de trabalho, no campo e na cidade, que transformaram significativamente sua paisagem (Loboda, 2008).

\subsection{Procedimentos metodológicos}

A vazão de um determinado rio tem como característica básica uma grande variabilidade temporal e espacial. Dessa forma, para analisar uma determinada série histórica de dados fluviométricos de um rio é necessário utilizar alguns valores estatísticos que resumem, em grande parte, o seu comportamento hidrológico. No presente estudo, a série histórica de vazões considerou o ano civil, a fim de garantir a independência dos valores amostrais de vazão, como apontado por Tucci (2000). Dessa forma, a avaliação estatística dos dados de vazão do rio das Pedras e a vazão ecológica foram determinadas por meio da aplicação dos seguintes métodos hidrológicos:

I - Vazão média mínima de sete dias com período de retorno de dez anos $\left({ }_{7} \mathrm{Q}_{10}\right)-\mathrm{A}_{7} \mathrm{Q}_{10}$ constitui um importante instrumento da Política Nacional dos Recursos Hídricos do Brasil, fornecendo estimativa estatística da disponibilidade hídrica dos escoamentos naturais de água. $\mathrm{O}$ valor da ${ }_{7} \mathrm{Q}_{10}$ foi obtido calculando-se as médias móveis das vazões diárias com período de sete dias ao longo de um ano hidrológico, sendo a vazão média mínima destas médias móveis retida. O processo foi repetido para cada ano da série histórica, obtendo-se uma série de valores mínimos de vazões médias em sete dias consecutivos. Estas vazões foram tabeladas em ordem crescente de magnitude juntamente com a frequência de ocorrência $(f)$ e o tempo de retorno, utilizando da equação de Weibull, $f=m / n-1$, em que $m$ é a ordem da vazão amostral e $n$ é o tamanho da amostra (Tucci, 1984), para a determinação da vazão mínima de sete dias com período de retorno de dez anos. $\mathrm{O}$ valor da ${ }_{7} \mathrm{Q}_{10}$ também foi obtido para conferência a partir de um gráfico com abcissas formadas pelo tempo de retorno e ordenadas correspondentes ao logaritmo das vazões. $\mathrm{A}_{7} \mathrm{Q}_{10}$ estimada a partir da equação de Weibull é uma das mais usadas (Sarmento, 2007) e precisa (Pinto et al., 2010).

II - Curva de permanência de vazões - a série histórica de vazões médias diárias por esse método é disposta em um gráfico, as quais são ordenadas de forma crescente. A permanência de cada vazão é o percentual de vezes em que ela foi equiparada ou extrapolada. Para caracterizar as descargas mínimas, foram consideradas as vazões associadas às permanências de $95 \%\left(\mathrm{Q}_{95} \%\right)$ e $90 \%\left(\mathrm{Q}_{90} \%\right)$, frequentemente utilizadas em projetos de outorga para uso da água (Pereira, 2004).

III - Vazões mínimas anuais de sete dias - esta vazão é obtida computando a média móvel das vazões mínimas com período de sete dias ao longo do ano hidrológico, durante a série considerada de dados (Benetti et al., 2003).

IV - Vazão aquática de base - este método calcula por meio da média da série histórica, considerando a vazão mediana do mês de menor débito fluvial do ano como valor mínimo de vazão ecológica a ser estabelecido (Kulik, 1990). Esta vazão corresponde ao fluxo de base do rio, sendo que na BHRP foi determinada calculando a mediana da vazão mensal mínima de cada ano (Longhi e Fomiga, 2011). 
VESTENA, L. R.; OLIVEIRA, E. D.; CUNHA, M. C.; THOMAZ, E. L. Vazão ecológica e disponibilidade hídrica na bacia das Pedras, Guarapuava-PR. Ambi-Agua, Taubaté, v. 7, n. 3, p. 212-227, 2012. (http://dx.doi.org/10.4136/ambi-agua.840)

Os dados de vazão diários utilizados foram os da estação fluviométrica (Figura 1) localizada na ETA (Estação de Tratamento de Água) - Guarapuava, nas coordenadas 2523'52"de latitude Sul e 51 26'09" de longitude Oeste, a $950 \mathrm{~m}$ de altitude, identificada pelo código Aneel (Agência Nacional de Energia Elétrica), de número 65809000.

Estes dados foram mensurados pela Agência Nacional das águas (ANA), tendo como recorte temporal neste estudo o período entre janeiro de 1985 a dezembro de 2009. Os dados foram tabulados, comparados e analisados, por meio de gráficos e tabelas.

A partir dos dados de vazão de referência, obtidas pelos quatros métodos anteriores foi determinada a vazão ecológica específica por meio da área de drenagem $\left(\mathrm{L} \cdot \mathrm{s}^{-1} \cdot \mathrm{km}^{-2}\right)$, pela relação entre a vazão ecológica determinada por cada um dos métodos pela área de drenagem da estação fluviométrica $\left(306 \mathrm{~km}^{2}\right)$.

A vazão máxima outorgável na seção do rio das Pedras para abastecimento público foi quantificada de forma expedita, da seguinte forma (Suderhsa, 2006):

$$
\begin{aligned}
& \mathrm{Q}_{\text {outorgável i }}=0,5 .\left(\mathrm{Q}_{95 \%}\right)_{\mathrm{i}}-\mathrm{Q}_{\text {não-disponível i }} \\
& \mathrm{Q}_{\text {não-disponível i }}=\sum \mathrm{Q} \text { outorgadas m }+\sum \mathrm{Q} \text { outorgadas } \mathrm{j}
\end{aligned}
$$

em que:

Qoutorgável i é a vazão máxima que pode ser outorgada na seção i do corpo hídrico; $\left(\mathrm{Q}_{95 \%}\right)_{\mathrm{i}}$ é a vazão natural com permanência de $95 \%$ do tempo na seção i; $\sum Q$ outorgadas m é o somatório das vazões outorgadas a montante da seção i; $\sum$ Q outorgadas j é o somatória das vazões outorgadas a jusante, que dependem da vazão na seção i. Uma vez que não existem outorgas cedidas nem a montante, nem a jusante da seção estuda pela Suderhsa, a $\mathbf{Q}_{\text {não-disponível i é igual }}$ a zero.

\section{RESULTADOS E DISCUSSÃO}

\subsection{Vazão fluvial}

O débito fluvial anual na BHRP, entre os anos de 1985 e 2009, apresentou uma média de 9,12 $\mathrm{m}^{3} \mathrm{~s}^{-1}$ e mediana de 9,16 $\mathrm{m}^{3} \mathrm{~s}^{-1}$. Os anos de $1998\left(17,07 \mathrm{~m}^{3} \mathrm{~s}^{-1}\right)$ e $1992\left(13,22 \mathrm{~m}^{3} \mathrm{~s}^{-1}\right)$ foram os que apresentaram as maiores vazões e os de $1985\left(3,64 \mathrm{~m}^{3} \mathrm{~s}^{-1}\right)$ e $2006\left(4,04 \mathrm{~m}^{3} \mathrm{~s}^{-1}\right)$ os de menores débitos fluviais (Tabela 1).

Tabela 1. Série de vazões médias anuais e vazões adimensionais (1985-2009).

\begin{tabular}{ccc|ccc|ccc}
\hline \multicolumn{7}{c}{ Estação Fluviométrica de Guarapuava - Código 65809000 } \\
\hline Ano & $\begin{array}{c}\text { Média anual } \\
\left(\mathbf{m}^{\mathbf{3}} \mathbf{~ s}^{-\mathbf{1}}\right)\end{array}$ & $\mathbf{Q}_{\mathbf{a} / \mathbf{Q}_{\mathbf{m}}}$ & $\mathbf{A n o}$ & $\begin{array}{c}\text { Média anual } \\
\left(\mathbf{m}^{\mathbf{3}} \mathbf{s}^{-\mathbf{1}}\right)\end{array}$ & $\mathbf{Q}_{\mathbf{a} / \mathbf{Q}_{\mathbf{m}}}$ & Ano & $\begin{array}{c}\text { Média anual } \\
\left(\mathbf{m}^{\mathbf{3}} \mathbf{~ s}^{-\mathbf{1}}\right)\end{array}$ & $\mathbf{Q}_{\mathbf{a}} \mathbf{Q}_{\mathbf{m}}$ \\
\hline 1985 & 3,64 & 0,39 & 1994 & 7,080 & 0,77 & 2002 & 8,64 & 0,94 \\
1986 & 5,08 & 0,55 & 1995 & 10,50 & 1,15 & 2003 & 6,59 & 0,72 \\
1987 & 8,04 & 0,88 & 1996 & 10,54 & 1,15 & 2004 & 8,02 & 0,87 \\
1988 & 4,99 & 0,54 & 1997 & 12,50 & 1,37 & 2005 & 10,14 & 1,11 \\
1989 & 12,93 & 1,41 & 1998 & 17,07 & 1,87 & 2006 & 4,04 & 0,44 \\
1990 & 12,03 & 1,31 & 1999 & 7,09 & 0,77 & 2007 & 9,05 & 0,99 \\
1991 & 5,57 & 0,61 & 2000 & 10,02 & 1,09 & 2008 & 9,16 & 1,00 \\
1992 & 13,22 & 1,44 & 2001 & 10,19 & 1,11 & 2009 & 11,06 & 1,21 \\
1993 & 10,97 & 1,20 & & & & & & \\
\hline
\end{tabular}

Nota: $\mathrm{Q}_{\mathrm{a}} \mathrm{Q}_{\mathrm{m}}$ - vazão adimensional determinada pela razão entre o total de vazão anual $\left(\mathrm{Q}_{\mathrm{a}}\right.$ e a média $\left(\mathrm{Q}_{\mathrm{m}}\right)$ das vazões da série histórica. 
VESTENA, L. R.; OLIVEIRA, E. D.; CUNHA, M. C.; THOMAZ, E. L. Vazão ecológica e disponibilidade hídrica na bacia das Pedras, Guarapuava-PR. Ambi-Agua, Taubaté, v. 7, n. 3, p. 212-227, 2012. (http://dx.doi.org/10.4136/ambi-agua.840)

Na Tabela 1, observam-se os valores de vazões médias anuais e as vazões adimensionais, determinada a partir da razão entre a vazão anual $\left(\mathrm{Q}_{\mathrm{a}}\right)$ e a vazão média $\left(\mathrm{Q}_{\mathrm{m}}\right)$ da série histórica. Esses dados foram plotados num gráfico (Figura 2) onde o eixo da abscissa representa os anos e o da ordenada a variação média das vazões, sendo que os valores acima de 1 representam anos com vazão acima da média e menor que 1 , abaixo da média.

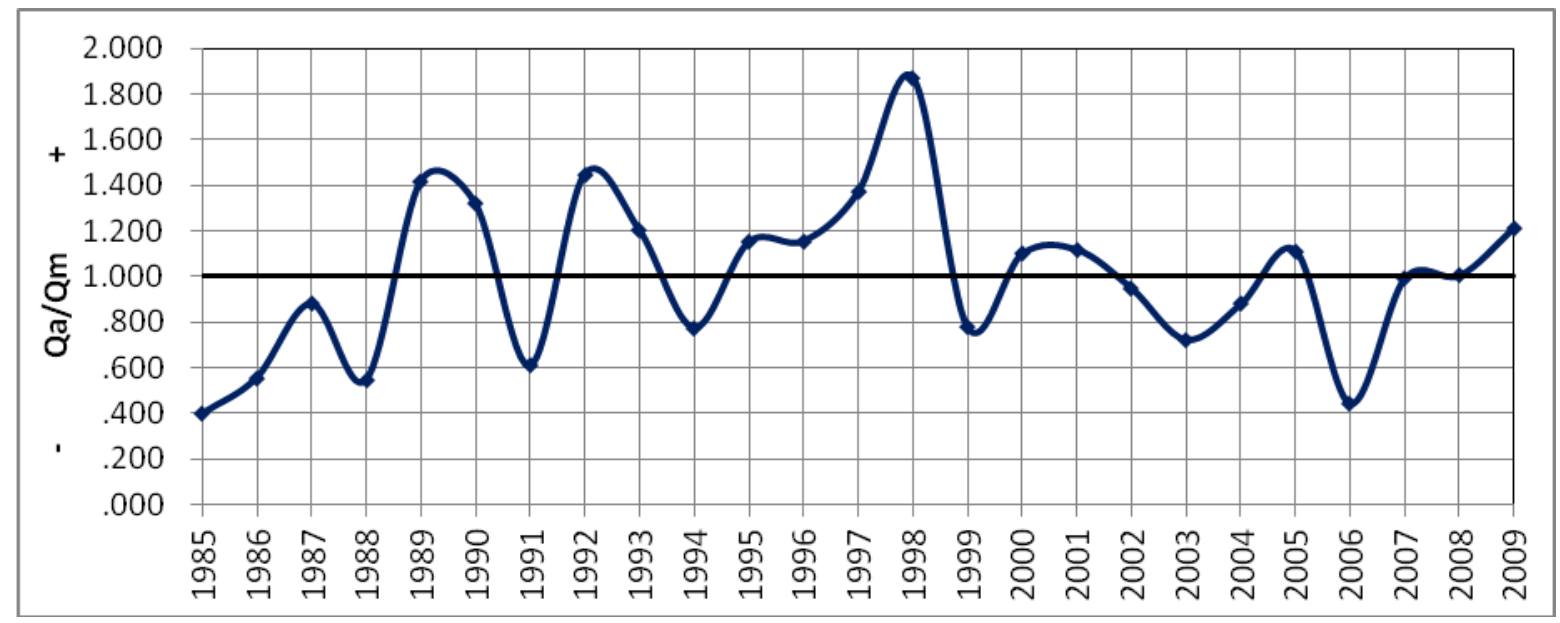

Figura 2. Variação da vazão adimensional no período de 1985 a 2009.

Pelos dados da Tabela 1 e da Figura 2, nota-se que a variação adimensional positiva e negativa do período esteve bem equilibrada, sendo que vazões acima da média ocorreram em 13 anos (52\% do período).

Como um dos principais fatores que influenciam a variação das vazões médias anuais, é a pluviosidade, ela também esteve nesse período muito influenciada pelos fenômenos El Niño e La Niña. Esta relação foi definida por Azevedo et al. (2005) que por meio de estudos na bacia do rio Iguaçu concluíram que a variabilidade pluvial da área está fortemente vinculada a estes fenômenos. Portanto, as anomalias das vazões médias estão em parte relacionadas à variação das entradas (precipitação) na bacia, com anos mais e menos secos.

Na Tabela 2 são apresentados os dados referentes à frequência das séries de vazões anuais, em classes intervalares de $4 \mathrm{~m}^{3} \mathrm{~s}^{-1}$, para melhor visualização dos dados. Nota-se que o intervalo de vazão compreendido entre 8 e $12 \mathrm{~m}^{3} \mathrm{~s}^{-1}$ abrangem quase metade (48\%) das vazões anuais da série histórica, sendo a mesma bem representativa do regime hidrológico anual na BHRP.

Tabela 2. Frequência das vazões anuais no rio das Pedras.

\begin{tabular}{c|ccc}
\hline $\begin{array}{c}\text { Classe } \\
\left(\mathbf{m}^{\mathbf{3}} \mathbf{s}^{-\mathbf{1}}\right)\end{array}$ & Fr. Absoluta & $\begin{array}{c}\text { Fr. Relativa } \\
(\mathbf{\%})\end{array}$ & $\begin{array}{c}\text { Fr. Acumulada } \\
(\boldsymbol{\%})\end{array}$ \\
\hline$<4$ & 02 & 08 & 8 \\
$4-8$ & 06 & 24 & 32 \\
$8-12$ & 12 & 48 & 80 \\
$12-16$ & 04 & 16 & 96 \\
$>16$ & 01 & 04 & 100 \\
\hline Total & $\mathbf{2 5}$ & $\mathbf{1 0 0}$ & $\mathbf{1 0 0}$ \\
\hline
\end{tabular}

Os dados fluviométricos mensais apresentaram uma média de $9,10 \mathrm{~m}^{3} \mathrm{~s}^{-1}$ e mediana de $8,80 \mathrm{~m}^{3} \mathrm{~s}^{-1}$. No entanto, há variações significativas ao longo do ano como se pode observar na Figura 3 que mostra um resumo mensal da série histórica. 
VESTENA, L. R.; OLIVEIRA, E. D.; CUNHA, M. C.; THOMAZ, E. L. Vazão ecológica e disponibilidade hídrica na bacia das Pedras, Guarapuava-PR. Ambi-Agua, Taubaté, v. 7, n. 3, p. 212-227, 2012. (http://dx.doi.org/10.4136/ambi-agua.840)

As menores médias mensais das vazões mínimas ocorreram nos meses de maio, junho e agosto. Entretanto, observaram-se as maiores médias mensais das vazões máximas também em maio, além de outubro e setembro, o que demonstra marcante variabilidade interanual no comportamento das vazões máximas e mínimas (Figura 3).

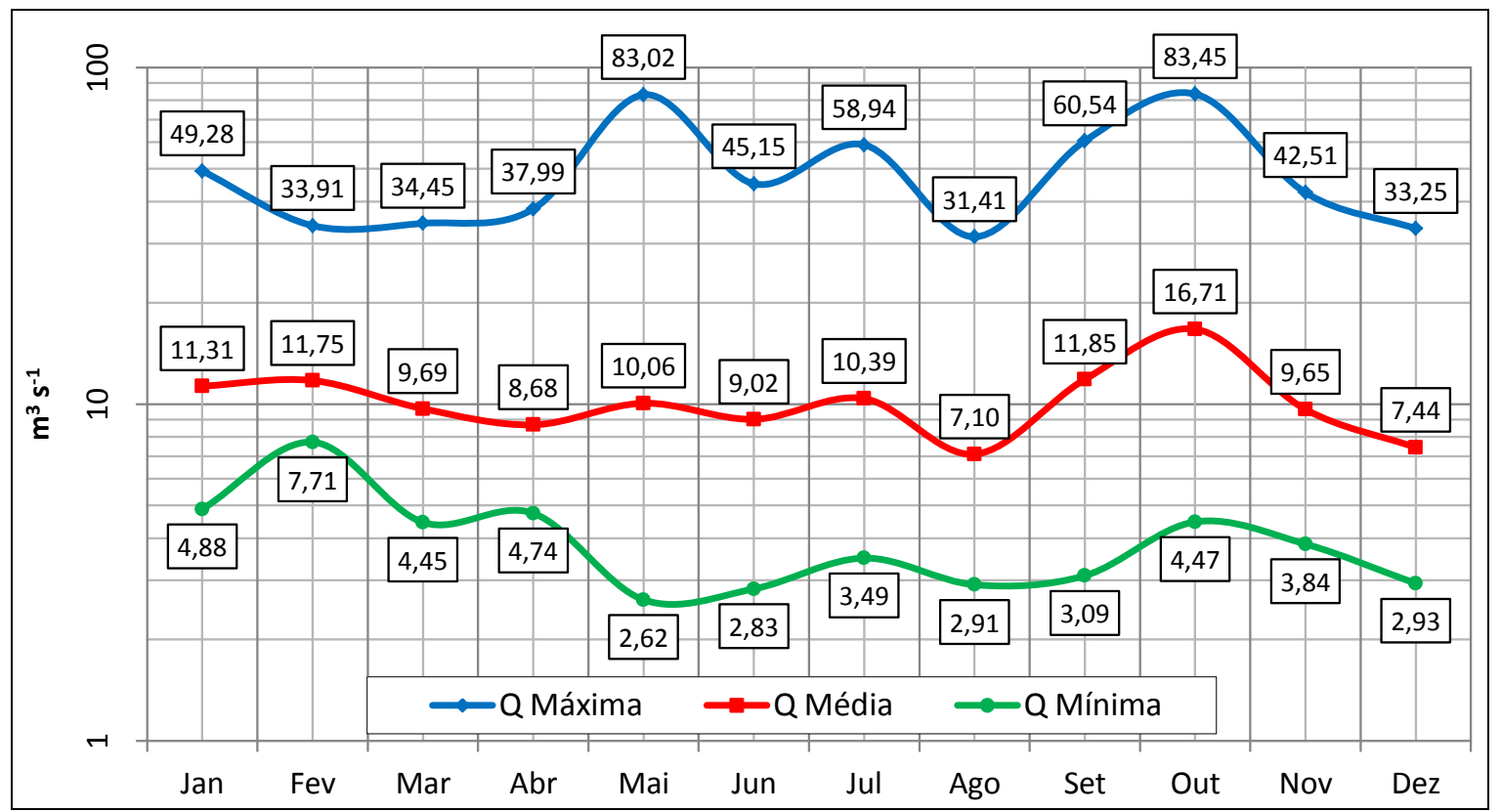

Figura 3. Valores médios das vazões mensais máximas, médias e mínimas do posto fluviométrico do rio das Pedras, no período de 1985 a 2009.

Fonte: Adaptado de ANA (2008).

\subsection{Vazão de referência a vazão ecológica}

\subsubsection{Vazão - ${ }_{7} \mathbf{Q}_{10}$}

Na Tabela 3 é mostrado o tempo de retorno ao longo de 25 anos da média das vazões mínimas obtidas ao longo deste período.

Tabela 3. Vazões mínimas anuais e o seu tempo de retorno (TR).

\begin{tabular}{|c|c|c|c|c|c|c|c|c|}
\hline \multicolumn{9}{|c|}{ Posto Fluviométrico de Guarapuava - Código 65809000} \\
\hline Ano & $\begin{array}{c}\text { Vazão } \\
{ }_{7} \mathbf{Q}_{10} \\
\left(\mathrm{~m}^{3} \mathbf{s}^{-1}\right) \\
\end{array}$ & $\begin{array}{c}\text { TR } \\
(\text { anos) }\end{array}$ & Ano & $\begin{array}{c}\text { Vazão } \\
{ }_{7} \mathbf{Q}_{10} \\
\left(\mathbf{m}^{3} \mathbf{s}^{-1}\right) \\
\end{array}$ & $\begin{array}{c}\text { TR } \\
(\text { anos) }\end{array}$ & Ano & $\begin{array}{c}\text { Vazão } \\
{ }_{7} Q_{10} \\
\left(m^{3} s^{-1}\right) \\
\end{array}$ & $\begin{array}{c}\text { TR } \\
\text { (anos) }\end{array}$ \\
\hline 1992 & 3,11 & 01 & 2002 & 1,83 & 10 & 2006 & 1,49 & 18 \\
\hline 1998 & 2,95 & 02 & 2005 & 1,83 & 11 & 2004 & 1,47 & 19 \\
\hline 2008 & 2,76 & 03 & 1997 & 1,78 & 12 & 1989 & 1,12 & 20 \\
\hline 2001 & 2,56 & 04 & 1987 & 1,69 & 13 & 1994 & 0,98 & 21 \\
\hline 2009 & 2,34 & 05 & 1995 & 1,59 & 14 & 1986 & 0,87 & 22 \\
\hline 2007 & 2,16 & 06 & 2000 & 1,54 & 15 & 1991 & 0,79 & 23 \\
\hline 1996 & 2,10 & 07 & 1999 & 1,52 & 16 & 1988 & 0,72 & 24 \\
\hline 1993 & 2,01 & 08 & 1990 & 1,50 & 17 & 1985 & 0,54 & 25 \\
\hline 2003 & 1,85 & 09 & & & & & & \\
\hline
\end{tabular}


VESTENA, L. R.; OLIVEIRA, E. D.; CUNHA, M. C.; THOMAZ, E. L. Vazão ecológica e disponibilidade hídrica na bacia das Pedras, Guarapuava-PR. Ambi-Agua, Taubaté, v. 7, n. 3, p. 212-227, 2012. (http://dx.doi.org/10.4136/ambi-agua.840)

Com os dados da tabela acima, em um gráfico foram plotados o tempo de retorno (TR) e as vazões mínimas anuais com intervalo de sete dias, sendo confirmado o valor da vazão ecológica de $1,83 \mathrm{~m}^{3} \mathrm{~s}^{-1}$ para ${ }_{7} \mathrm{Q}_{10}$ (Figura 4).

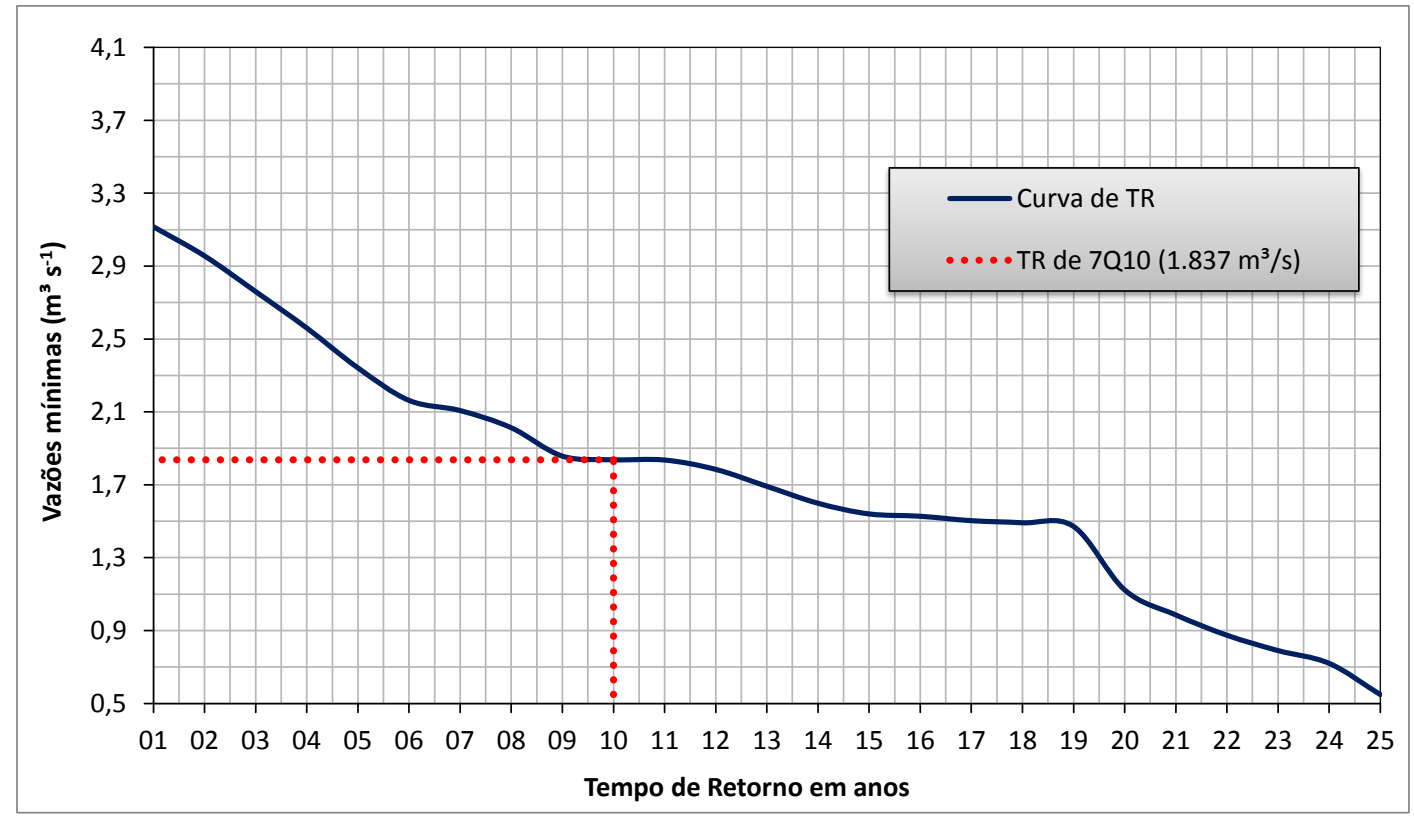

Figura 4. Tempo de retorno das vazões mínimas.

\subsubsection{Curva de permanência}

A curva de permanência permite visualizar de imediato a potencialidade natural do rio, destacando a vazão mínima e o grau de permanência das diferentes magnitudes de vazão. No gráfico da Figura 5 é apresentada a curva de permanência mensal na estação fluviométrica de Guarapuava. As vazões de permanência de $95 \%$ e $90 \%$ correspondem ao valor de vazão de referência à vazão ecológica de $2,22 \mathrm{e} 2,74 \mathrm{~m}^{3} \mathrm{~s}^{-1}$, respectivamente.

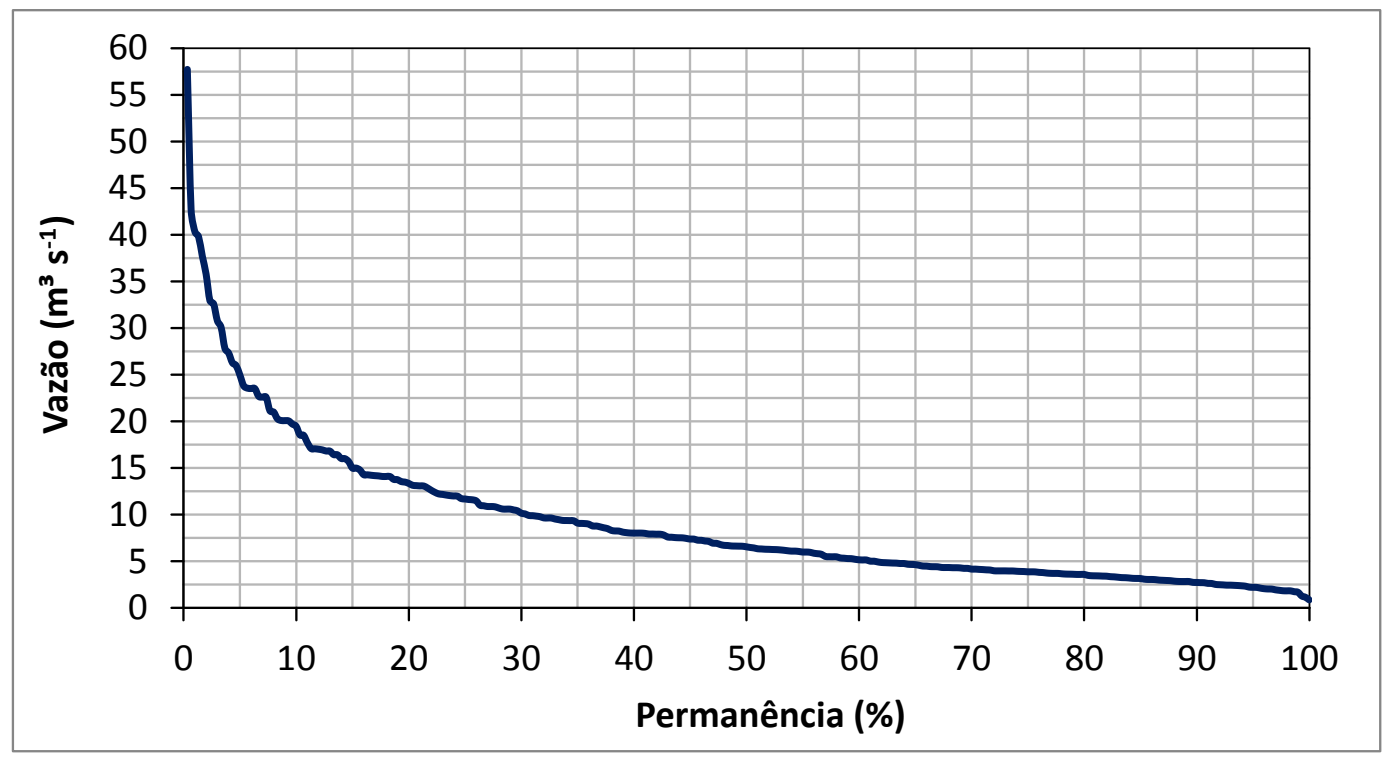

Figura 5. Permanência dos valores mensais de vazões do rio das Pedras (1985-2009). 
VESTENA, L. R.; OLIVEIRA, E. D.; CUNHA, M. C.; THOMAZ, E. L. Vazão ecológica e disponibilidade hídrica na bacia das Pedras, Guarapuava-PR. Ambi-Agua, Taubaté, v. 7, n. 3, p. 212-227, 2012. (http://dx.doi.org/10.4136/ambi-agua.840)

\subsubsection{Média das vazões anuais mínimas de sete dias}

A vazão determinada pela média móvel das vazões diárias mínimas com intervalo de sete dias ao longo do ano corresponde ao valor de $1,72 \mathrm{~m}^{3} \mathrm{~s}^{-1}$, ou seja, a vazão de referência à concessão de outorga.

\subsubsection{Vazão aquática de base}

Pelos dados da Tabela 4 foi determinada a vazão de $2,50 \mathrm{~m}^{3} \mathrm{~s}^{-1}$ como a vazão de referência à vazão ecológica da seção do rio das Pedras na qual se tem aproveitamento da água para abastecimento da cidade de Guarapuava.

Tabela 4. Mediana das vazões mensais mínimas.

\begin{tabular}{cc|cc|cc}
\hline Ano & $\begin{array}{c}\text { Vazão } \\
\left(\mathbf{m}^{\mathbf{3}} \mathbf{s}^{-\mathbf{1}}\right) \\
\text { mediana }\end{array}$ & Ano & $\begin{array}{c}\text { Vazão } \\
\left(\mathbf{m}^{\mathbf{3}} \mathbf{s}^{\mathbf{- 1}}\right) \\
\text { mediana }\end{array}$ & Ano & $\begin{array}{c}\text { Vazão } \\
\left(\mathbf{m}^{\mathbf{3}} \mathbf{s}^{-\mathbf{1}}\right) \\
\text { mediana }\end{array}$ \\
\hline 1985 & 0,78 & 1994 & 1,77 & 2002 & 2.19 \\
1986 & 2,39 & 1995 & 1,78 & 2003 & 2.53 \\
1987 & 2,06 & 1996 & 2,85 & 2004 & 3.01 \\
1988 & 1,14 & 1997 & 2,12 & 2005 & 2.25 \\
1989 & 2,81 & 1998 & 3.54 & 2006 & 1.92 \\
1990 & 2,89 & 1999 & 1.80 & 2007 & 2.57 \\
1991 & 1,67 & 2000 & 3.83 & 2008 & 3.61 \\
1992 & 4,31 & 2001 & 2.39 & 2009 & 2.83 \\
1993 & 3,43 & \multicolumn{7}{l}{} \\
\hline \multicolumn{7}{l}{ Média da série histórica $\left(\mathbf{m}^{\mathbf{3}} \mathbf{s}^{-\mathbf{1}}\right)$} \\
\hline
\end{tabular}

\subsubsection{Vazão ecológica na BHRP}

A vazão ecológica específica foi determinada (relação entre a vazão ecológica e a área de drenagem) por possibilitar a comparação desta em diferentes áreas (bacias hidrográficas) ( $\mathrm{L} \mathrm{s}^{-}$ ${ }^{1} \mathrm{~km}^{-2}$ ) (Tabela 5).

Tabela 5. Vazão ecológica específica da BHRP.

\begin{tabular}{|c|c|c|c|c|c|c|c|c|}
\hline \multirow[b]{2}{*}{ Vazão } & \multirow[b]{2}{*}{ Unidade } & $\begin{array}{c}\text { Método } \\
1 \\
\end{array}$ & \multicolumn{2}{|c|}{$\begin{array}{c}\text { Método } \\
2\end{array}$} & \multirow{2}{*}{\begin{tabular}{l}
\multicolumn{1}{c}{ Método } \\
\multicolumn{1}{c}{$\mathbf{c}$} \\
Média anual \\
das $Q$ mín. \\
de 7 dias
\end{tabular}} & \multirow{2}{*}{$\begin{array}{c}\begin{array}{c}\text { Método } \\
4\end{array} \\
\text { Vazão } \\
\text { aquática } \\
\text { de base }\end{array}$} & \multirow[b]{2}{*}{ Média } & \multirow{2}{*}{$\begin{array}{c}\text { Coeficiente de } \\
\text { variação } \\
(\%)\end{array}$} \\
\hline & & ${ }_{7} \mathbf{Q}_{10}$ & $\mathbf{Q}_{90}$ & $\mathbf{Q}_{95}$ & & & & \\
\hline $\begin{array}{c}\text { Vazão } \\
\text { ecológica }\end{array}$ & $\mathrm{m}^{3} \mathrm{~s}^{-1}$ & 1,83 & 2,74 & 2,22 & 1,72 & 2,50 & 2,20 & 19,66 \\
\hline $\begin{array}{c}\text { Vazão } \\
\text { ecológica } \\
\text { específica }\end{array}$ & $\mathrm{L} \mathrm{s}^{-1} \mathrm{~km}^{-}$ & 6,00 & 8,95 & 7,25 & 5,64 & 8,16 & 7,20 & 19,47 \\
\hline
\end{tabular}

A seção da estação fluviométrica drena uma área de $306 \mathrm{~km}^{2}$, sendo que a partir dos quatro métodos hidrológicos aplicados, a vazão de referência à vazão ecológica específica variou de 8,95 a $5,64 \mathrm{~L} \mathrm{~s}^{-1} \mathrm{~km}^{-2}$, com uma média de 7,20 $\mathrm{L} \mathrm{s}^{-1} \mathrm{~km}^{-2}$ e um coeficiente de variação média de 19,47\% (Tabela 5). Os menores volumes foram obtidos pelos métodos da média anual das vazões mínimas de sete dias e da ${ }_{7} \mathrm{Q}_{10}$, com 1,72 e $1,84 \mathrm{~m}^{3} \mathrm{~s}^{-1}$, 
VESTENA, L. R.; OLIVEIRA, E. D.; CUNHA, M. C.; THOMAZ, E. L. Vazão ecológica e disponibilidade hídrica na bacia das Pedras, Guarapuava-PR. Ambi-Agua, Taubaté, v. 7, n. 3, p. 212-227, 2012. (http://dx.doi.org/10.4136/ambi-agua.840)

respectivamente. Enquanto, as vazões ecológicas obtidas pelos métodos da curva de permanência de vazões e vazão aquática de base foram bem maiores, 2,74 e $2,50 \mathrm{~m}^{3} \mathrm{~s}^{-1}$, respectivamente.

\subsection{Vazão ecológica e outorga: disponibilidade hídrica}

O Instituto de Águas do Paraná com base em estudos de 1985 estabeleceu a ${ }_{7} \mathrm{Q}_{10} \mathrm{em}$ bacias de até $5.000 \mathrm{~km}^{2}$ de área para todas as regiões do Estado do Paraná (ÁGUAS PARANÁ, 2011). Com base nesses dados, a região abrangida pela BHRP apresentou uma ${ }_{7} \mathrm{Q}_{10}$ de aproximadamente $2,50 \mathrm{~L} \mathrm{~s}^{-1} \mathrm{~km}^{-2}$. Ela divergiu das ${ }_{7} \mathrm{Q}_{10}$ estimada para a BHRP, com valor de $6,00 \mathrm{~L} \mathrm{~s}^{-1} \mathrm{~km}^{-2}$. Tal valor subestimado deve estar relacionado ao fator escala relacionado à extrapolação da ${ }_{7} \mathrm{Q}_{10}$ para a área da BHRP, dado que a área da bacia abrange pouco mais de $300 \mathrm{~km}^{2}$, enquanto que a média estadual foi obtida para bacias de até 5.000 km² (ÁGUAS PARANÁ, 2011).

Dados fornecidos por técnicos da Companhia de Saneamento do Paraná - Sanepar, unidade de Guarapuava, mostram que a outorga de exploração de água no rio das Pedras pela companhia para o abastecimento urbano é de $1.800 \mathrm{~m}^{3} / \mathrm{h}\left(0,5 \mathrm{~m}^{3} \mathrm{~s}^{-1}\right)$, com regime de bombeamento de $15 \mathrm{~h}$ por dia. Contudo, os mesmos já solicitaram um acréscimo do valor da outorga, alegando que a vazão do rio tem aumentado, assim como a demanda da cidade de Guarapuava. Cabe ressaltar, que esta outorga tem validade de 20 anos com término para 17 de junho de 2013.

Pelos dados de bombeamento d'água, foi definida uma vazão de exploração (captação) média diária de $0,31 \mathrm{~m}^{3} \mathrm{~s}^{-1}$, valor que está abaixo do valor outorgado. No entanto, destaca-se que o valor é médio, e que se tratando de vazão ecológica é necessário considerar os valores extremos mínimos no rio.

De acordo com os critérios adotados no Estado do Paraná, a vazão ecológica é $50 \%$ da ${ }_{7} \mathrm{Q}_{10}$, estimada no presente estudo em $0,91 \mathrm{~m}^{3} \mathrm{~s}^{-1}\left(3.306,60 \mathrm{~m}^{3} \mathrm{~h}^{-1}\right)$. Um dos métodos avaliados que apresentou o valor de vazão ecológica menor (Tabela 5).

A vazão máxima outorgável para abastecimento público, de acordo com o método empregado pelo Instituto de Águas do Paraná (equação 1 e $2-50 \%$ da $\mathrm{Q}_{95}$ ), é de $1,11 \mathrm{~m}^{3} \mathrm{~s}^{-1}$, na seção do rio das Pedras, bem acima do valor atualmente outorgado a Sanepar, que é de $0,50 \mathrm{~m}^{3} \mathrm{~s}^{-1}$.

Diante dos resultados, subtraiu-se da vazão diária monitorada a vazão outorgada $\left(0,5 \mathrm{~m}^{3} \mathrm{~s}^{-1}\right)$ para verificar a vazão ecológica. Os dados foram plotados em um gráfico para comparação (Figura 6). Nela verifica-se que a vazão no trecho fluvial em determinados períodos fica abaixo da vazão ecológica estabelecida oficialmente, que é de $0,91 \mathrm{~m}^{3} \mathrm{~s}^{-1}$ no Estado do Paraná, assim como da vazão ecológica média dos métodos avaliados $\left(2,20 \mathrm{~m}^{3} \mathrm{~s}^{-1}\right)$.

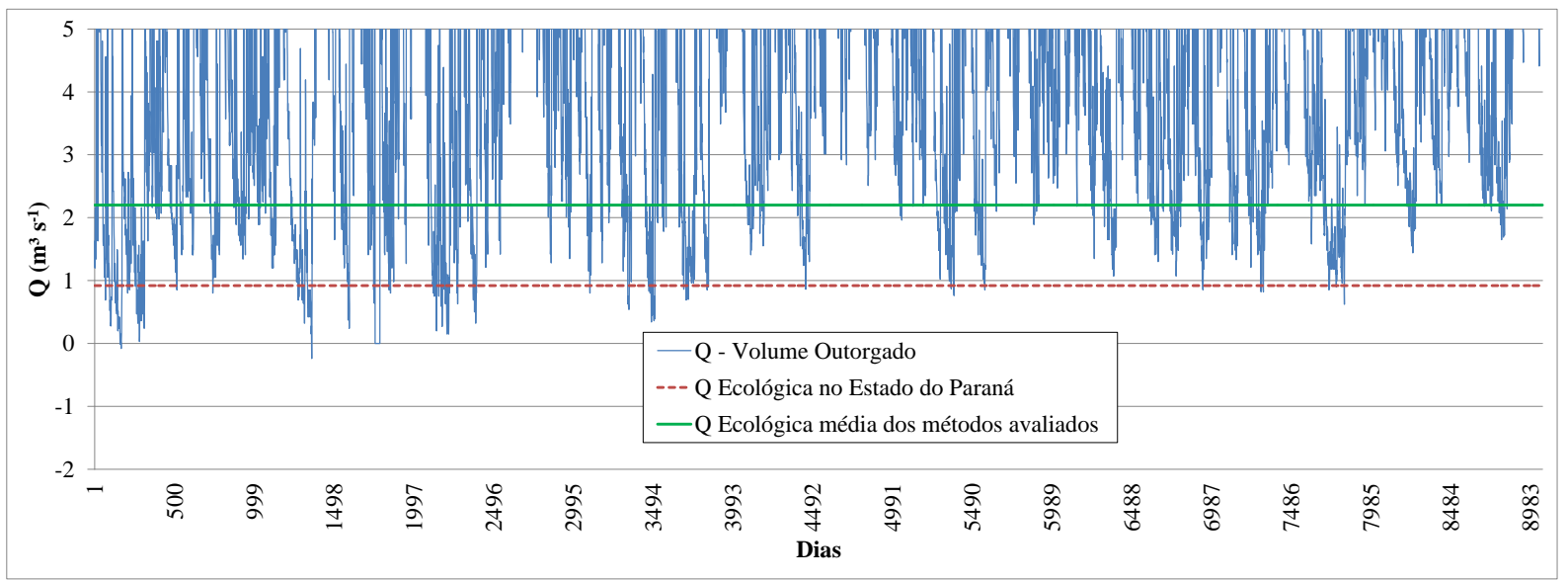

Figura 6. Dados de vazão diária menos o volume outorgado. 
VESTENA, L. R.; OLIVEIRA, E. D.; CUNHA, M. C.; THOMAZ, E. L. Vazão ecológica e disponibilidade hídrica na bacia das Pedras, Guarapuava-PR. Ambi-Agua, Taubaté, v. 7, n. 3, p. 212-227, 2012. (http://dx.doi.org/10.4136/ambi-agua.840)

Constata-se, pela Figura 6, que a variabilidade temporal da vazão impõe condições diferenciadas ao aproveitamento hídrico, dispondo de maiores volumes nos períodos de cheias e menores nos de estiagem. Ela também demonstra a limitação da metodologia adotada para definição da vazão ecológica no Estado do Paraná, como também das demais metodologias empregadas no estudo, uma vez que a vazão ecológica deve conservar os níveis mínimos de fluxo de base especialmente nos períodos de secas, por considerar as prioridades ecológicas, o comportamento do fluxo e a limitação para explotação de água, como destacaram Deitch et al. (2009). Destaca-se também que estudos realizados por Stalnaker et al. (1995) já apontavam que a vazão ${ }_{7} \mathrm{Q}_{10}$ é excessivamente baixa para a manutenção de hábitats aquáticos.

Com base nos resultados obtidos, resume-se que a BHRP apresenta uma série de dados hidrológicos com poucas falhas o que dá confiabilidade aos dados monitorados, a saber:

- a vazão de referência à vazão ecológica na BHRP variou de 1,7 a 2,7 $\mathrm{m}^{3} \mathrm{~s}^{-1}$, de acordo com as especificidades de cada um dos quatro métodos aplicados;

- a vazão ecológica no trecho do rio das Pedras, segundo critérios estabelecidos no Estado do Paraná, que é $50 \%$ da ${ }_{7} \mathrm{Q}_{10}$ é de $0,92 \mathrm{~m}^{3} \mathrm{~s}^{-1}$;

- a vazão de referência específica à vazão ecológica variou de 5,64 a $8,10 \mathrm{~L} \mathrm{~s}^{-1} \mathrm{~km}^{-2}$, com uma média de $6,97 \mathrm{~L} \mathrm{~s}^{-1} \mathrm{~km}^{-2}$, considerando as quatro metodologias;

- a vazão de outorga média utilizada na bacia é de $0,31 \mathrm{~m}^{3} \mathrm{~s}^{-1}$ e a cedida de $0,50 \mathrm{~m}^{3} \mathrm{~s}^{-1}$, com perspectivas de aumentar dado o crescimento da cidade e consequentemente da demanda.

Os resultados reforçam a afirmação de Collischonn et al. (2005) que demostram a insuficiência do tradicional critério de vazão ecológica como um valor único, válido para todas as épocas e estações do ano. Esses autores também apresentam uma metodologia alternativa que vem sendo aplicada em alguns casos nos EUA, focada em vários aspectos do regime hidrológico (Hidrograma Ecológico) e não apenas em vazões mínimas.

Apesar de o valor médio estar abaixo da Outorga, o crescimento urbano e o consequente aumento de demanda por quantidade de água, o volume de água retirado tende a aumentar, o que requer novos estudos hidrológicos dos impactos ambientais, bem como a procura por outras alterativas potenciais para o abastecimento de Guarapuava, a fim de minimizar os impactos tanto de ordem social, econômica e ecológica.

\section{CONCLUSÃO}

Os resultados desse estudo indicaram a ineficiência dos métodos de determinação da vazão ecológica, ou seja, não garantem o volume de água mínimo necessário à conservação do ecossistema fluvial. Portanto, com a manutenção do sistema e a evolução nas técnicas de monitoramento fluviométrico, novas análises devem ser implementadas para avaliar com mais precisão as alterações espaciais e também temporais dos processos hidrológicos.

Os métodos utilizados para definição das vazões de referências à vazão ecológica mostraram-se de fácil aplicação, entretanto, baseiam apenas em dados de séries históricas de vazão, na quantidade de água, sem considerar a biota do rio e do ecossistema do seu entorno. Portanto, novos estudos sobre a vazão ecológica devem ter por base também o conhecimento da biota do curso d'água e suas relações.

Os conhecimentos prévios das vazões ecológicas e dos processos envolvidos proporcionam subsídios que fundamentam a tomada de decisões e ajudam num planejamento e manejo do uso racional dos recursos hídricos, permitindo adequar os fatores socioeconômicos aos ecológicos. 
VESTENA, L. R.; OLIVEIRA, E. D.; CUNHA, M. C.; THOMAZ, E. L. Vazão ecológica e disponibilidade hídrica na bacia das Pedras, Guarapuava-PR. Ambi-Agua, Taubaté, v. 7, n. 3, p. 212-227, 2012. (http://dx.doi.org/10.4136/ambi-agua.840)

\section{AGRADECIMENTOS}

Os autores agradecem a CAPES - Coordenação de Aperfeiçoamento de Pessoal de Nível Superior, pela concessão de bolsas de estudo em nível de mestrado a dois dos autores.

\section{REFERÊNCIAS}

AZEVEDO, L. C.; NERY, J. T.; MARTONI, A. M. Análise da precipitação pluvial associada ao fenômeno El-Niño na bacia hidrográfica do Rio Iguaçu - Paraná, In: SIMPÓSIO BRASILEIRO DE GEOGRAFIA FÍSICA APLICADA, 11, 04-09 Set 2005, São Paulo. Anais... São Paulo: USP, 2005, p. 1904-1913.

BENETTI, A. D.; LANNA, A. E.; COBALCHINI, M. S. Metodologias para determinação de vazões ecológicas em rios. Revista Brasileira de Recursos Hídricos, Porto Alegre, v. 8, n. 2, p. 149-160, abr./jun. 2003.

BRASIL. Lei Federal no 9.433, de 08 de janeiro de 1997, Institui a Política Nacional de Recursos Hídricos, cria o Sistema Nacional de Gerenciamento de Recursos Hídricos. Diário Oficial da República Federativa do Brasil, Brasília, DF, 08 jan. 1997.

BRASIL. Resultado do Censo do Instituto Brasileiro de Geografia e Estatísticas (IBGE) de 2010. Governo Federal. Diário Oficial da República Federativa do Brasil, Brasília, DF, 04 nov. 2010.

COLliSCHONN, W.; AGRA, S. G.; FREITAS, G. K.; PRIANTE, G. R.; TASSI, R.; SOUSA, C. F. Em busca do Hidrograma Ecológico. In: XVI SIMPÓSIO BRASILEIRO DE RECURSOS HÍDRICOS, 16, 20-24 Nov. 2005, João Pessoa. Anais... João Pessoa: ABRH, 2005. 1 CD-ROM.

CRUZ. R. C. Prescrição de vazão ecológica: aspectos conceituais e técnicos para bacias com carência de dados. 2005. 135f. Tese (Doutorado em Ecologia) - Instituto de Biociências, Universidade Federal do Rio Grande do Sul, Porto Alegre, 2005.

DEITCH, M. J.; KONDOLF, G. M.; MERENLENDER, A. M. Hydrologic impacts of small scale instream diversions for frost and heat protection in the California wine country. River Research and Applications, v. 25. p. 118-134, 2009.

INSTITUTO DE ÁGUAS DO PARANÁ. Outorga de Uso Recursos Hídricos. Disponível em: http://www.aguasparana.pr.gov.br/modules/conteudo/conteudo.php?conteudo=10. Acesso em 05 fev. 2012.

INSTITUTO DE ÁGUAS DO PARANÁ: Vazões Mínimas. Disponível em: http://www.aguasparana.pr.gov. br/arquivos/File/mp13.pdf. Acesso em: 8 mai. 2011.

JOWETT, I. G. Instream flow methods: A comparison of approaches. Regulated Rivers: Research and management. v. 13, p. 115-127, 1997.

KULIK. B. H. A method to refine the New England aquatic base flow policy. Rivers. v.1, n. 1, p. 8-22, 1990.

LOBODA, C. R. Práticas Socioespaciais e Espaços Públicos em Guarapuava-Pr. 2008. 352 f. Tese (Doutorado em Geografia) - Faculdade de Ciências e Tecnologia. Universidade Estadual Paulista, Presidente Prudente, 2008. 
VESTENA, L. R.; OLIVEIRA, E. D.; CUNHA, M. C.; THOMAZ, E. L. Vazão ecológica e disponibilidade hídrica na bacia das Pedras, Guarapuava-PR. Ambi-Agua, Taubaté, v. 7, n. 3, p. 212-227, 2012. (http://dx.doi.org/10.4136/ambi-agua.840)

LONGHI, E. H.; FORMIGA, K. T. M. Metodologias para determinar vazão ecológica em rios, Revista Brasileira de Ciências Ambientais, n. 20, p. 2176-9478, jun. de 2011.

MAACK, R. Geografia Física do Estado do Paraná. $3^{a}$ ed. Curitiba: Imprensa oficial, 1981, $440 \mathrm{p}$.

MEDEIROS, P. C.; SOUZA, F. A. S.; RIBEIRO, M. M. R. Aspectos conceituais sobre o regime hidrológico para a definição do hidrograma ambiental. Ambi-Agua, Taubaté, v. 6, n. 1, p. 131-147, 2011. http://dx.doi.org/10.4136/ambi-agua.179

MOLIERE, D. R.; LOWRY, J. B. C.; HUMPHREY, C. L. Classifying the flow regime of data-limited streams in the wet-dry tropical region of Australia. Journal of Hydrology, v. 367, p. 1-13, 2009. http://dx.doi.org/10.1016/j.jhydrol.2008.12.015

PARANÁ. Legislação Paranaense de Recursos Hídricos: Lei Estadual no 12.726/99 e decretos que estruturam a gestão de recurso hídrica no Estado do Paraná. São Paulo: Astúrias, 2002. 169 p.

PARANÁ. Portaria No 20/99 - SUDERHSA, de 18 de Maio de 1999. Dispõe sobre critérios para outorga de recursos hídricos superficiais. DOE. n. 5503, Curitiba, 26 mai. 1999.

PEREIRA, S. B. Evaporação no lago de Sobradinho e disponibilidade hídrica no rio São Francisco. 2004. 105 f. Tese (Doutorado em Recursos Hídricos e Ambiental) Departamento de Engenharia Agrícola, Universidade Federal de Viçosa, Viçosa - MG, 2004.

PINTO, L. C.; MACHADO, E. F. P.; DE MELlO, C. R.; SILVA, A. M. Análise de Distribuições de Probabilidades e Estimativa da $\mathrm{Q}_{7,10}$ para a Região do Rio Itabapoana, Espírito Santo/Rio De Janeiro. In: XIX CONGRESSO DE PÓS-GRADUAÇÃO DA UFLA, 19, 27 set. - 01 out. 2010. Lavras. Anais... Lavras: UFLA, 2010.

SANTOS, A. F.; KOBIYAMA, M. Contribuição potencial de cargas poluentes na bacia do Rio das Pedras, no município de Guarapuava - PR. Revista Ciências Exatas e Naturais, v. 5, n. 1, p. 33-46, Jan/Jun. 2003.

SARMENTO, R. Estado da arte da vazão ecológica no Brasil e no mundo. Unesco/ANA/CBHSF, 2007. 38 p.

SALNAKER,C.; LAMB, B. L.; HENRIKSEN,J.; BOVEE, K.; BARTHLOW, J. The Instream Flow Incremental Methodology. A Primer for IFIM. U.S. Department of Interior. National Biological Service, Washington, D. C., 1995. 47 p.

STRAHLER, A. N. Quantitative analysis of watershed Geomorphology. Am. Geophys. Union Trans., v. 38, n. 6, p. 913-920, 1957.

SUDERHSA. Superintendência de Recursos Hídricos e Saneamento Ambiental. Manual Técnico de Outorgas. Novembro/2006 - Revisão 01. Disponível em: http://www.aguasparana.pr.gov.br/arquivos/File/manual_outorgas.pdf. Acesso em 06/02/2012.

THOMAZ, E. L.; VESTENA, L. R. Aspectos Climáticos de Guarapuava-PR. Guarapuava: UNICENTRO, 2003. $106 \mathrm{p}$.

TUCCI, C. E. M. Metodologia para regionalização de vazões. Vol. II: Regionalização de vazões do Alto Paraguai. Porto Alegre: IPH/UFRGS, 1984. 
VESTENA, L. R.; OLIVEIRA, E. D.; CUNHA, M. C.; THOMAZ, E. L. Vazão ecológica e disponibilidade hídrica na bacia das Pedras, Guarapuava-PR. Ambi-Agua, Taubaté, v. 7, n. 3, p. 212-227, 2012. (http://dx.doi.org/10.4136/ambi-agua.840)

TUCCI, C. E. M. Água no Meio Urbano. In: REBOUÇAS, A. et. al, (eds.) Águas Doces do Brasil: capital ecológico, uso e conservação. 2. ed. São Paulo: Escrituras Ed., 2000, p. 475-508.

VESTENA, L. R.; THOMAZ, E. L. Avaliação de conflitos entre áreas de preservação permanentes associadas aos cursos fluviais e uso da terra na bacia do rio das pedras, Guarapuava-PR. Ambiência, v. 2, n. 1, p. 73-85, 2006 